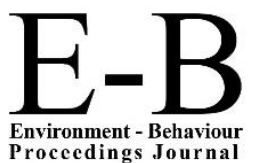

Environment - Behaviour
Procecdings Journal
CSSR 2018

https://cssr.uitm.edu.my/2018/

5th International Conference on Science and Social Research

Le Meridien Kota Kinabalu Hotel, 5 - 6 December 2018

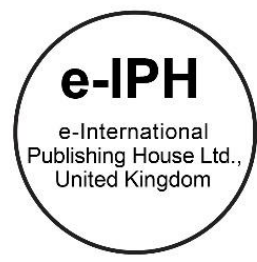

\title{
Nopoh Bukau Ritual by the Orang Asli of Che Wong in Kampung Senil, Kuala Gandah, Pahang
}

\author{
Fatin Nazihah Rosli', Sabki Md Noh²
}

${ }_{1}$ Postgraduate Research Student, Faculty of Art \& Design, Universiti Teknologi MARA, 40450 Shah Alam, Selangor, Malaysia

2 Faculty of Art and Design, Universiti Teknologi MARA, 42300 Puncak Alam, Selangor, Malaysia

fatinnrosli@yahoo.com, sabkimdnoh@yahoo.com

Tel: +60142208984

\begin{abstract}
'Nopoh' is a traditional singing séance practice by the Che Wong aborigines community of Peninsular Malaysia. Modernisation had taken over their traditional lifestyle culture, especially to the young generation. There only some of the elders still maintain knowledge and is practising it. If there is no action taken in preserving it, all this traditional knowledge will be buried together with knowledgeable elders when they die. This study focused on ritual practice during the forest-flowering season to examine and analyse the data collected through audio-visual documentation of the ritual. The results revealed the significance of the ritual benefits to the community.
\end{abstract}

Keywords: Orang Asli; Che Wong; Singing Séance; Culture performance

eISSN: 2398-4287@ 2020. The Authors. Published for AMER ABRA cE-Bsby e-International Publishing House, Ltd., UK. This is an open access article under the CC BYNC-ND license (http://creativecommons.org/licenses/by-nc-nd/4.0). Peer-review under responsibility of AMER (Association of Malaysian Environment-Behaviour Researchers), ABRA (Association of Behavioural Researchers on Asians) and cE-Bs (Centre for Environment-Behaviour Studies), Faculty of Architecture, Planning \& Surveying, Universiti Teknologi MARA, Malaysia.

DOI: https://doi.org/10.21834/ebpj.v5iSI3.2575.

\subsection{Introduction}

Every Orang Asli has its own unique cultures, lifestyles and languages. It is also unique to the Orang Asli of Che Wong in Kuala Gandah, Pahang. As emphasised by Howell (1984) "Che Wong cosmology is extremely rich, their relationship with the supernatural world is remarkably complex, and the degree of detail contained in their traditional knowledge". They have been practising such knowledge in their daily lives. It has to be observed and frequently questioned to understand their beliefs and values. Thus, by staying longer and continually communicating with the people, one will extract useful knowledge of their traditional cultural practice. Such practice is not always obviously seen nor commonly heard by us outsiders. Even amongst the Che Wong community themselves, this conventional artistic practice is seldom watched or even participated, especially at the urban settlement area of Che Wong in Kuala Gandah. It only happens on rare occasions such as when modern the medicine cannot cure sure of their sickness, or when someone in the community had passed away. The Che Wong community will only participate in such a ritual event that is led by the Che Wong elders who mostly stay deep in the forest of Krau.

According to Kardooni, et al. (2014), "forest is the source of their livelihood, shapes of their customs and culture define their identity, and constitutes their local environment." Thus, this might explain that they have a very close link with nature, especially their environment, the forests, and rivers. However, every Orang Asli has its own identity and way of practising their cultures. "Their themes,

eISSN: 2398-4287C 2020. The Authors. Published for AMER ABRA cE-Bsby e-International Publishing House, Ltd., UK. This is an open access article under the CC BYNC-ND license (http://creativecommons.org/licenses/by-nc-nd/4.0/). Peer-review under responsibility of AMER (Association of Malaysian Environment-Behaviour Researchers), ABRA (Association of Behavioural Researchers on Asians) and cE-Bs (Centre for Environment-Behaviour Studies), Faculty of Architecture, Planning \& Surveying, Universiti Teknologi MARA, Malaysia. DOI: https://doi.org/10.21834/ebpj.v5iSI3.2575. 
rhythms, style and narrative structure are unique to each particular Orang Asli group." (Nicholas, 2004). Apart from that, "the indigenous Che Wong cosmology, including myths, songs and range of prescriptions and proscriptions, used to structure the everyday life of the Che Wong" (Lillegraven, 2006). "The Orang Asli create stories and narratives not only to make sense of the world but to impart important social and ethical mores to ensure community living and continuity." (Nicholas, 2004). Lillegraven and Nicholas seem to be at the same perceptions that when the Orang Asli practise, it benefits them for a great living community.

The most common well-known of Orang Asli traditional cultural practice is their singing séance or known as the sewang. This singing séance is a ritual practised by the Orang Asli to communicate spirituality with the supernatural being. However, every tribe of Orang Asli in Peninsular Malaysia has its unique ways of performing this ritual, that meets a variety of purposes. This sing and dance are led by the elderly shaman together with a team of traditional percussion musicians. Most of the singing séance will be practice during the dark hour, usually after sunset, to make contact with the supernatural being. In the Che Wong language, 'nopoh' is a term that refers to the singing séance. The nopoh will perform during the ceremony of healing the sickness or days after mourning the death. Besides that, the nopoh ritual will also work during the fruiting tree seasonal in the forest, such as during the paddy fruiting season, fruit tree fruiting or flowering season. From January until July, the Che Wong community will perform the 'nopoh bukau or flower singing seance ritual to make contact with the spiritual superhuman being. The word 'Bukau', means flower in Che Wong language, and the reason for performing such ritual is to request from the supernatural being to blossom more flowers in the forest for its beauty and the bounty harvest for the incoming fruits season. According to Kardooni et al. (2014), "as a consequence of the rapid change in the natural environment followed by economic, political, and cultural change on a global scale, many indigenous knowledge systems are in danger of vanishing." As we are mesmerised by the amazingly rich and unique indigenous culture of the Che Wong, have we ever wondered whether this kind of traditional knowledge will always be inherited by the young and future generation of Che Wong?

\subsection{Problem of the Study}

Modernisation had slowly overtaken the traditional lifestyle culture of the Che Wong community. Exposure to modernisation is inevitable and should not be blamed on their lack of these traditional practices. As emphasised by Fadli et al. (2012), "the young generation has already lost interest and have no desire to maintain the tradition of their native visual arts because they are now already exposed to outside modern influences and are having trouble maintaining their cultural identity". These changes were already evident in the village in Kuala Gandah, where when the Government resettled the majority of the Che Wong community. Most of the people had shifted from their traditional cultivator/farmer and hunter practices to a now salaried labour job. While, a small minority of the Che Wong prefers to remain and live in the forest like their ancestors, continue cultivating and hunting. "I was told that there was no putao (shaman) in the village anymore. This might explain the reluctance among the Che Wong to identify any living person as putao." (Lillegraven, 2006). However, the researcher was told by the Che Wong that there are only a few elders who are actively trying to sustain their traditional cultural practice, and some of them are Che Wong putao. They instead live deep in the forest of Krau with their family. According to Lillegraven (2006), "the youngster do not know the traditional myths and songs; they are not very familiar with the Che Wong cosmology anymore". Well, this is the problem faced by the elders of Che Wong in preserving their traditional cultural practice.

\subsection{Objective of the Study}

The objective of this research is:

1. To explore the singing séance of Nopoh Bukau traditional ritual by Che Wong during the flower season.

2. To document the Nopoh Bukau ritual by Che Wong during the flower season.

\subsection{Significant of the Study}

Che Wong is like other indigenous people who transmit their traditional knowledge orally, and such knowledge could eventually be lost from memory or forgotten. However, oral tradition can be sustained to continued by preserving it through technology, having it recorded through audio-visual recording devices and documented on paper for reference to the future generation. Therefore, this study aims to produce documentation as a contribution to the Che Wong community as a source of their traditional nopoh bukau ritual performance. The data collected is also intended to acknowledge and to preserve this full traditional knowledge of the Che Wong community for the benefit of the young generation. The audio-visual technology can also help them to observe and listen from the playback many times during the learning session. They may be able to watch and study in detail all the ritual movements, actions, the accompanying music, and lyrics over and over again. It is hoped that this study would benefit the Che Wong community and their future generations as well as the researchers. By pursuing the objective of this study, the extent to which the needs of learners currently met, and ways of raising their interest in visual documentation produced. The processed aimed in increasing the awareness and interest in the visual documentation of traditional cultures, particularly to those already under threat.

\subsection{Literature Review}

Nopoh as a singing séance either for healing or contacting a spiritual superhuman being. (Howell, 1982). "The Che Wong will conduct many singing sessions (nopoh) for the sole purpose of pleasing the bi asal (supernatural being) when they see that the blossom season is approaching" (Howell, 1984). She also explains that "during a séance, humans request their spirit guides to come and to help them. Various preparations were made to entice them" (Howell, 1989). Men and women sit together in a group as they provide 
the percussion accompaniment by drumming bamboo struck on a piece of wood. The woven art crafts are part of the paraphernalia made for the performance. Variety shapes of wearable crafts woven from the palm leaves are made, especially as attractions and offer to the superhuman. Each song has a rhythmic pattern (Howell, 1984). Besides, the songs sung by them form part of the oral literary tradition handed down from their ancestors, and the lyrics contain stories of legends and histories.

Fadli Razak (2014) asserts that "the people no longer practised their traditional belief system". Therefore, observation on the culture of Che Wong is so limited, and that it cannot survive long without concrete action of documentation, Needham (1955) argues: "it is our duty to record, while we have the chance, as much as we can learn on Siwang (Che Wong) culture and social organisation. However, Fadli (2012), drew attention to the usefulness of reference materials such as video and print media in providing continuity of their ancestor's stories of their people, and eventually maintaining the originality of theory of visual arts. This is because audio and visual recording devices are now able to capture in detail all the techniques, actions, practices, stories, language, songs and dances.

\subsection{Methodology}

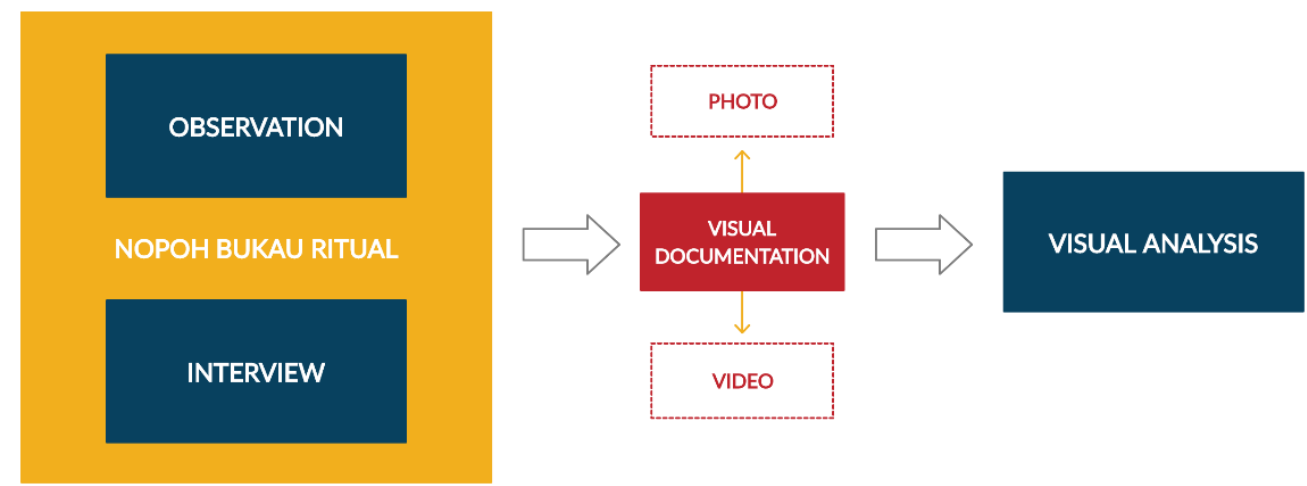

Fig. 1: Research Method

The aim of the study had brought this research into a qualitative research method, through the approach of ethnographic research. However, this study does not aim to test or to analyse any theory but to explore, explain and document the nopoh bukau ritual practice by Che Wong community in Kampung Senil, Kuala Gandah, Pahang. The data collected through observations, interviews, and visual analysis. Howell (1984) stated that "since there are so little ceremony and ritual, an understanding of their values and beliefs had to be reached more from talking than from observing." Due to this reason, the researcher observed the ritual and frequently asked related questions directly to the respondents. Spending time socialising with the people and follow their daily activities would catch their untold stories. According to Lillegraven (2006), she did not do interviews as she doubted its futility. However, she transformed from a formal question into simple questions and answers. Therefore, Howell and Lilligraven approached applied in this research.

Additionally, this research also applied digital audio-visual instrument in gaining more data. The application of digital devices using photo and video has helped the researcher to capture the specific behaviour of the Che Wong people effectively. These digital instruments documented the languages, actions, and attire of participants. During the analysis of the nopoh bukau ritual, the documented visual projected back to them. It is to stimulate conversations about their cultural identities, stories, and perceptions.

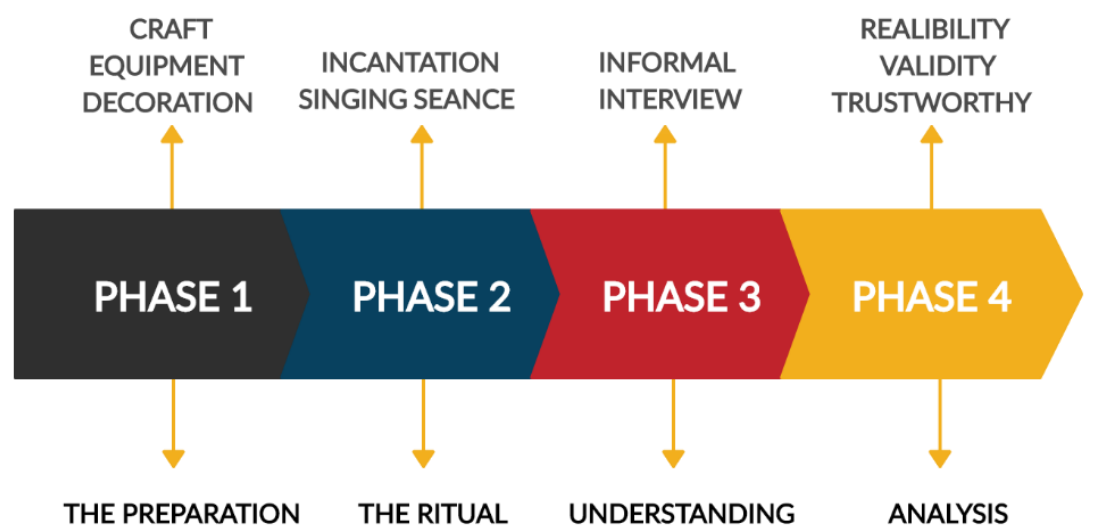

Fig. 2: Phases of the Nopoh Bukau ritual 
Four phases are drawn up in the plan for collecting data during the fieldwork. Phase One centred on the preparation of nopoh bukau ritual. Woven wearable ritual craft, equipment and decorations were prepared during these phases before they begin the ritual. Phase Two is when all the visuals and audio of the nopoh bukau ritual captured with the digital audio-visual equipment. This is where the ritual started with the incantations and then the singing séance. All of these documented visuals were then brought to Phase Three, which meant to begin soliciting for a more in-depth understanding of the ritual-an informal interview conducted with the community, especially the participants. An informal interview approach was made, and much insightful information can be obtained through a casual conversation, especially when a digital audio recorder is not within sight. Phase Four is when the analysis part is purposely to obtain the validity and reliability, ensuring the finding has it is trustworthiness using a combination of method and data triangulation technique. Triangulation technique can produce a conflicting result, requiring additional data and an effort to reconcile the information (Fetterman, 2010). Thus, the validity of the finding was gathered during the nopoh bukau ritual practice and the reliability gained during the interview with the participants. The interwoven of observation, together with visual documentation, interviews and analysis, strengthen the evidence of the findings which gained its trustworthiness. The figure 3 shows the triangulation approached for

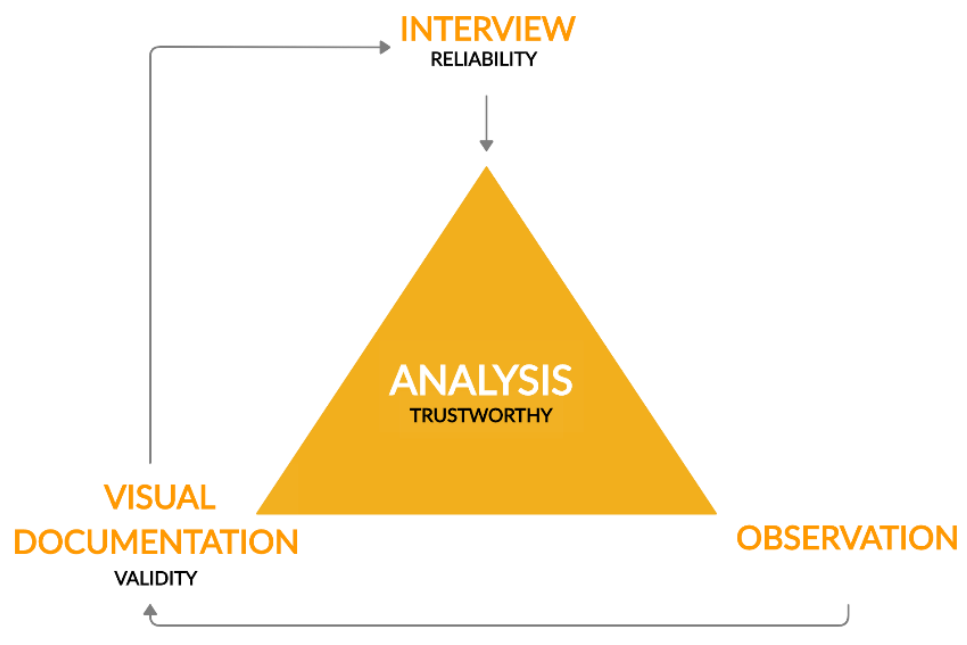

this research.

Fig.3: The triangulations of the Nopoh Bukau ritual

\subsection{Result and Discussion}

\subsection{What is Nopoh Bukau?}

The word 'nopoh' translated in Che Wong language by Howell (1984) is a singing séance for healing or contacting the supernatural being. While the word 'bukau' in Che Wong, means flower. During the beginning of flower season, the Che Wong conducts the singing séance ritual purposely to please the bi asal and bi hali to blossom the during the pollinating season and give abundant of fruit during the coming fruit season in the forest. The bi asal and bi hali are the Che Wong supernatural and the human eye cannot see them. The bi asal are the people whom they believe descended from the Earth 6th Level. Those people used to live on the Earth 7th level where we human are living right now. However, they will all move back to Earth 6 th level because it is much colder as compared to Earth 7 th Level. While, the bi hali or leaf people is a supernatural being, who lives on the mountain, on hills, on trees, on a leaf, and on flowers. These are the supernatural known as 'bunian' or 'orang halus' in the Malay language.

The Nopoh bukau will be performed during dark hours, just immediately after the sunset. No lights are at all permitted during this ritual performance. Any other intervening light source might chase away the supernatural from entering the ritual places. The main reason for the nopoh bukau is to welcome the bi hali and bi asal to descend and enter. They performed the ritual for two nights, will rest for two nights and continue again for another two nights afterwards. They will sing several songs related to fruits and animals. All closes families and friends will be invited during the ritual to be merry during the nopoh. The ritual was performed inside their hut because the nopoh bukau does not require any dancing. However, it can also be performed outdoor if they so desire.

\subsection{Supernatural presents during the Nopoh Bukau}

In the Che Wong fable stories, they believed that there was once a tall tree, which has so many types of fruits that were brought up to Earth 6th level by Bujang Kumar. These fruits will no longer exist in Earth 7th level unless the humans request from them. Therefore, during the nopoh bukau ritual, putao (shaman) will send friendly ruwai (soul) up to the Earth 6th level to meet the bi asal, requesting abundant of fruits in the Earth 7 th as in the Earth 6th.

The $b i$ hali or leaf people, on the other hand, is the supernatural that lives in the flowers and leaves of trees and plants on Earth 7th level. When the nopoh bukau is performed, the bi hali will come to the location of the nopoh. They will then see that our home filled with woven flowers and leaf. Bi hali will feel jealous towards our beautiful homes that filled with the decorative woven craft. The Che Wong will then ask for in return, from a gift of their paraphernalia productions to the bi hali. With their paraphernalia gifts, the bi hali will then produce plenty

of fruits and flowers. 


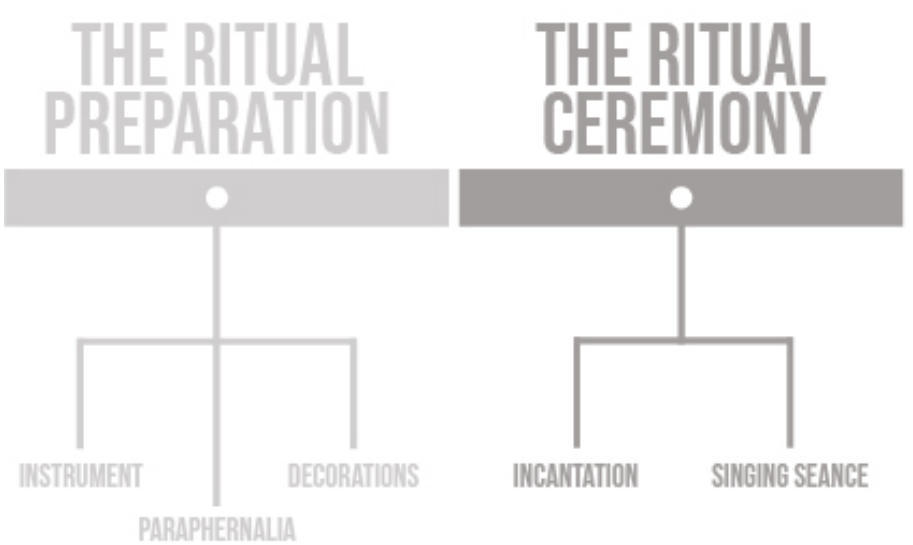

\subsection{The Ritual Preparation and the Nopoh Bukau Ritual}

Fig. 4: The flow process of Nopoh Bukau

The diagram in Figure 4 shows the flow process, which the flow process divided into three phases of nopoh bukau. The phases are the Pre-ritual which is more focused on the preparation of the nopoh bukau, and the Actual-ritual is the activity of Che Wong during the night of the ritual. The post-ritual phase is the Data gathering, based on the observation, informal interview and visual documentations.

The first phase is where the Che Wong prepares the equipment for the ritual. This phases will include the percussion instrument which is made from two blocks of bamboo, crafted woven paraphernalia, and the woven decorations. These are palm leaves woven into a variety of shapes. All paraphernalia made has its purposes and meaning. It represents the trunks, branches, twigs and flowers that turned into the supernatural being. The more the decorative flowers are produced and received by the supernatural, the more the flowers will bloom and flourish in the flowering season. That will then be followed up by abundant fruit harvest on the next fruits season. All these presented for the supernaturals, especially to the bi hali. They decorate the woven craft outside and inside of their hut, and some of that they will wear it on their body too. According to Kueh (2016), the bi hali will come and hang around the roads, huts and flowers that were hung there. Apart from that, other tools will be used by them all.

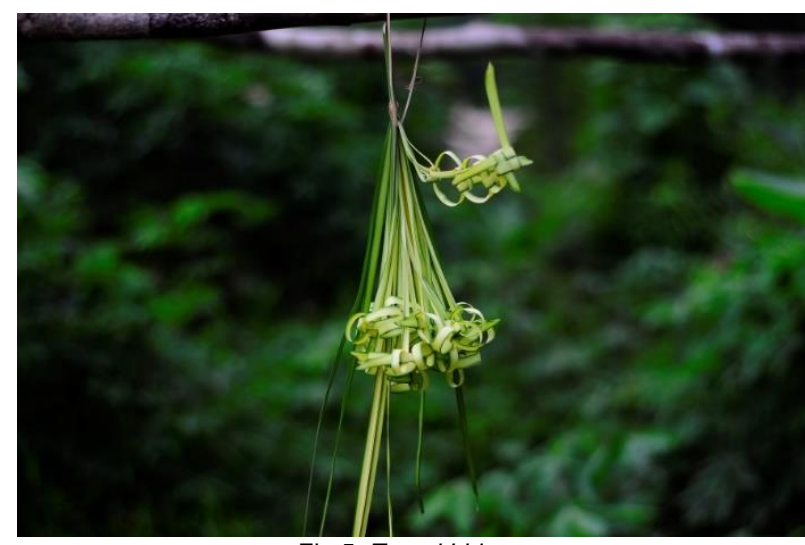

Fig.5: Tumpi Lideng

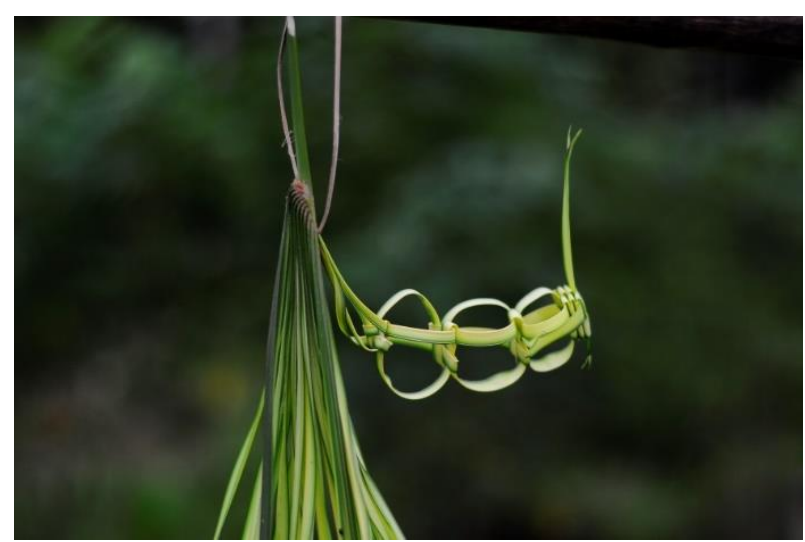

Fig.6: Balai Koh 


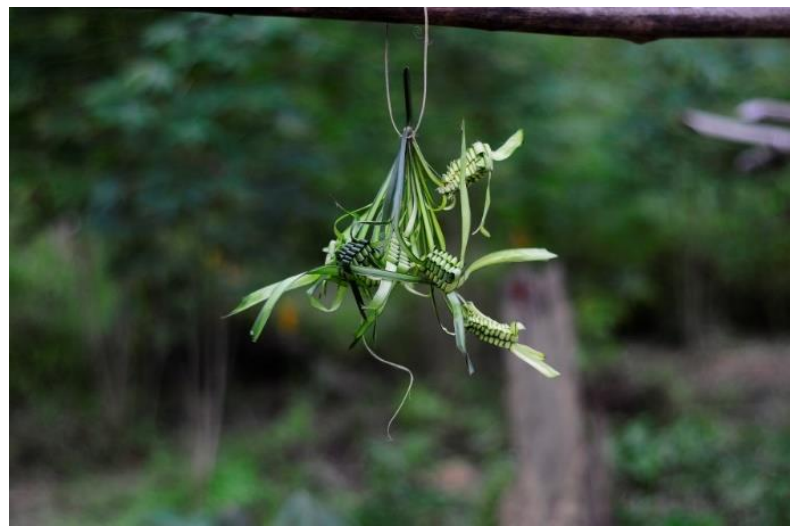

Fig.7: Sung Kumoi

Tumpi Lideng is a kind of palm leaf woven craft in the shape of cotton flowers. This palm leaf woven craft has to be produced in large quantities so that more flowers will flourish in the coming season. Balai Koh dan Sung Kumoi explicitly created as a stopover for the bi hali. According to their tales, when the ritual is performed, and the bi hali approach the ritual location, they will enter into the Balai Koh and Sung Kumoi as a stopover. The people of Che Wong will produce many of these Balai Koh and Sung Kumoi as they believe many bi hali will come during the nopoh performance.

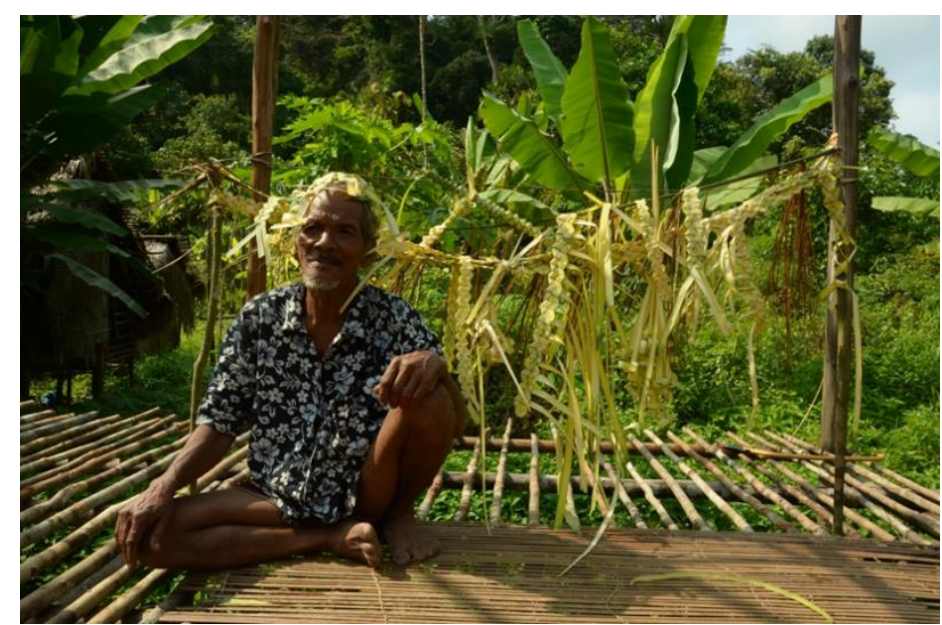

Fig.8: Mr Kueh with his decorated paraphernalia

Next, the second phase is when the actual ritual started. The shaman will begin with the tankal. Tankal is a form of spell or invocation (Howell, 1982). It is a traditional way of confronting with the supernatural being by asking permission and request through the invocation. Then after, the musicians will begin to strike the pair of bamboo stumps on a piece of woodblock and the putao start to sing the first song. There are no limits to the number of songs to sing for one night. It will just depend on the putao's capability. There will be songs about fruits, animals, and also songs about the supernatural being. Each song has its own rhythmic pattern. According to Mr Kueh (the shaman), the song is a myth or history of Che Wong people back in the old days. It also contains lessons that can be learned from it. Apart from that, their song explains the existence of their cosmology too (2016). 


\subsection{Timeframe of the Nopoh Bukau Ritual}

Usually, they will perform the duration of six days for the nopoh bukau; two days of singing performed after sunset, another two days of rest, and followed with two more days of singing after sunset. On the first day of the nopoh bukau, the researcher observed that they sang several songs. During the documentation, they sang three songs, and on the second day, they sang eight songs. Then they rested for two days to engage in their daily activities. On the fifth day, they sang the same songs from the first night and on the sixth day they sang the same song on the second day again.

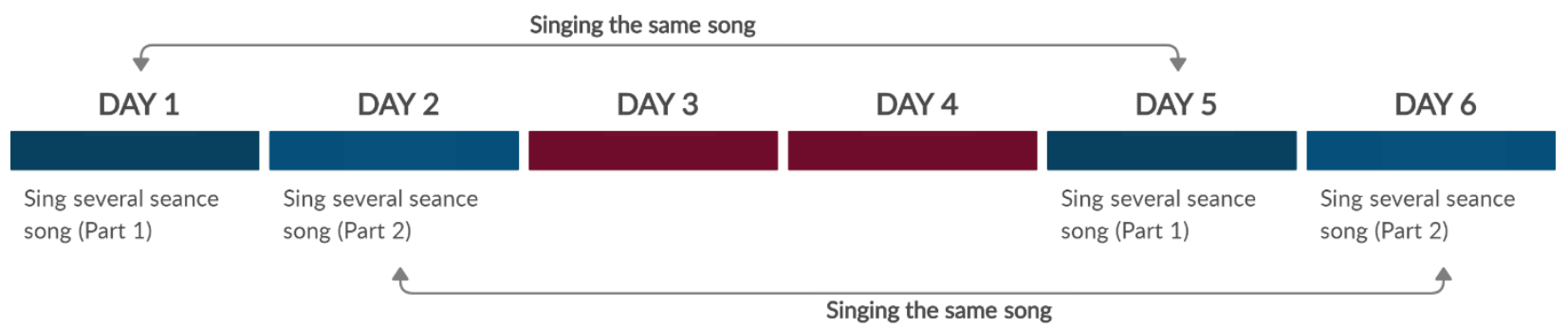

Fig.9: Timeframe of the Nopoh Bukau

Significantly, we understand that such ritual performed may benefit in so many ways. When practices like these are carried out, the practitioners of the rituals are also preserving their traditional culture. The present research has shown that modern digital research technology could be harnessed to document traditional cultures and indigenous practices for archival to not only younger generations of the community but also for the world to know. Many people felt that modernisation has contributed to the loss of traditional Orang Asli culture. Nevertheless, this research argues that modernisation has introduced many new technologies in the form of electronic gadgets for recording and sharing information. These technologies can be applied to preserve traditional culture.

\subsection{Conclusion and Recommendation}

In conclusion, through all aspect of the nopoh bukau practice, from preparation to its ritual, the Che Wong is living a balanced life with nature and the supernatural being. Che Wong traditional culture practice contains art in their craft, performing, as well as tales. While their songs representing models of their belief and their identity explained in their songs. Overall, we understand that nopoh bukau practice has a great relationship with nature. Therefore, indirectly, Che Wong is a great holder of environmental sustainers. If used skillfully, modern technology could arouse interest in rituals and traditional cultures among the younger generation who tend to be more technology-savvy today than their elders who are more familiar with the oral tradition. It will be great if both generations can work together to preserve and maintain these traditional practices.

Besides the nopoh bukau ritual, the Che Wong people also do perform many other types of traditional ritual practices too. Hence froth there is still many more ritual practice yet remained unexplored and undocumented. It is a hoped that in future, more research could be investigated using with better equipment in archiving these dyingly traditional cultural knowledge and many more new researchers will collaborate with the cultural study. Not only with the elders but also will attract the Che Wong youth into exploring new ways of preserving and archiving their unique traditional cultural practice.

\section{Acknowledgements}

The authors gratefully acknowledge the Universiti Teknologi MARA (UiTM Shah Alam) for the financial research support rendered through GIP grant (600-IRMI/GIP 5/3 (0072/2016).

\section{References}

Fadli A. Razak, Adzrool I.I., Kamarudzaman M.I. \& Mustaffa H. A. (2012). The Impact of Che Wong Tribe Resettlement through Image Representation: The Documentation of Che Wong Tribe at Kuala Gandah, Lanchang Pahang, Malaysia. International Proceedings of Economics Development and Research. 51, 187-190.

Fetterman, D. M. (2010) 3rd Edition. Ethnography: Step-by-Step. California: Sage Publications.

Fui, L. H. (1997). Orang Asli, Forest and Development. Kuala Lumpur: Perpustakaan Negara Malaysia.

Howell, S. (1982/1983). Chewong Myths and Legends. Kuala Lumpur: Art Printing Works Sdn Bhd.

Howell, S. (1984). Society and Cosmos: Chewong of Peninsular Malaysia. Singapore: Oxford University Press.

Howell, S. \& Willis, R. (1989). To Be Angry Is Not To Be Human, but To Be Fearful Is: Chewong concepts of Human Nature. Societies at Peace: Anthropological Perspectives. https://cas.uab.edu/peacefulsocieties/wpcontent/uploads/sites/6/2015/11/Howell 89.pdf 
Rosli, F.N., \& Md Noh, S., CSSR2018, 5th International Conference on Science and Social Research, Le Meridien Kota Kinabalu Hotel, 5 - 6 Dec 2018, E-BPJ, 5(SI3), Dec 2020 (pp.381-388)

Kardooni, R., Fatimah Kari, Siti R.Y. \& Siti H.Y. (2014). Traditional knowledge of Orang Asli on Forest in Peninsular Malaysia. Indian Journal of Traditional Knowledge. 13(2), 283-291. http://nopr.niscair.res.in/bitstream/12345689/27915/1//JTK\%2013\%282\%29\%20283291.pdf

Lillegraven, A.L. (2006). Paths of Change in Field of Power (Master's Thesis). https://www.duo.uio.no/bitstream/handle/10852/16572/ pathsx.pdf?sequence=1 